\title{
An Assessment of Health Priorities Among a Community Sample of Somali Adults
}

\author{
Ahmed A. Mohamed ${ }^{1}$ (D) Kiley Lantz ${ }^{1} \cdot$ Yahye A. Ahmed ${ }^{1} \cdot$ Ahmed Osman $^{2} \cdot$ Mohamud A. Nur $^{1} \cdot$ Omar Nur $^{3}$. \\ Jane W. Njeru' ${ }^{1}$ Irene G. Sia ${ }^{1} \cdot$ Mark L. Wieland ${ }^{1}$
}

Accepted: 15 February 2021 / Published online: 19 March 2021

(c) The Author(s), under exclusive licence to Springer Science+Business Media, LLC, part of Springer Nature 2021

\begin{abstract}
Somali immigrants are one of the largest African populations to resettle in the United States since 1990. There is an emerging literature base of disease-specific studies among Somali immigrants. However, we are aware of no studies on the health priorities for Somalis from the community's perspective. Somali adults in Minnesota completed a survey conducted by a community-based participatory research partnership on individual and community health priorities. Data were reported as counts and frequencies. 646 participants completed the survey. The most important health issues for individuals and their families were health behaviors (22.7\%), diabetes (18.2\%), and hypertension (14.4\%), while those of the community were diabetes $(22.5 \%)$, hypertension (18.8\%) and weight (15.9\%). This study found a significant overlap of health priorities among Somali individuals and their families compared to the community. These health priorities underscore the need to focus on non-communicable diseases among Somali immigrants.
\end{abstract}

Keywords Somali $\cdot$ Health priorities $\cdot$ Immigrant and refugee health $\cdot$ CBPR

\section{Background}

Health priorities for the Somali population in the United States (US) have been changing since their arrival to the US in the early 1990s. Somali populations have consistently been in the top three total number of African refugees immigrating to the United States over the past three decades and were the second largest group of refugees from Africa in 2019 [1,2]. Initial studies on Somali health focused on communicable diseases such as tuberculosis, hepatitis, and parasitic infections in the context of migration from high prevalence regions [3-6]. This focus on communicable diseases is prevalent in the literature on refugee populations more broadly [7]. Yet, previous research has consistently demonstrated a high prevalence of chronic conditions among

Ahmed A. Mohamed

mohamed.ahmedshafii@mayo.edu

1 Department of Medicine, Mayo Clinic, 200 1st Street SW, Rochester, MN 55905, USA

2 Intercultural Mutual Assistance Association, Rochester, MN, USA

3 Somali American Social Service Association, Rochester, MN, USA refugees to the US, including diabetes, hypertension, and obesity [8-10].

Most studies of Somali health in the US are derived from medical records review of individual healthcare institutions. Population-based data and national surveys do not contain the necessary granularity to distinguish Somali participants from other African Americans. Therefore, the voices of Somali refugees have been under-represented in health needs assessments.

Two previous studies have explicitly assessed Somali health priorities. The first was a qualitative study in Bristol, England, in which 10 interviews and two focus groups were conducted with Somali adults [11]. The specific health concerns identified included the need for information about vitamin D deficiency, breastfeeding, the use of khat and female genital mutilation. Communication needs and service provision were also identified as health priorities. The second was a qualitative study in Kansas City, Missouri in which 11 interviews were conducted with Somali adults [12]. Chronic diseases and mental health were identified as health priorities. We are aware of no large-scale survey-based studies on the health priorities of Somalis from the community's perspective in the US. 
The Health Belief Model (HBM) formed the theoretical background of this study, as back-drop to the Community Organization model. The HBM, developed in the 1950s by social psychologists to explain why so few people were participating in programs to prevent and detect disease, identifies six constructs that influence people's readiness to act in disease prevention. At the individual level, perceived susceptibility to a disease or condition and its severity are the first two constructs for the framework, key to designing both short-term and long-term behavior change strategies. A deep understanding of how susceptible a population feels to a health problem, and whether they believe it is serious, are critical and foundational, and precede the other constructs (perceived benefits and barriers to recommended action, cue to action and self-efficacy), in the development of interventions. Community Organization Models emphasize community-driven approaches to assessing and solving health and social problems, and in the context of this study, the Community based participatory research CBPR approach was used to assess the health concerns at the community level [13].

CBPR partnerships are uniquely suited to surfacing these health priorities [14]. CBPR is an approach to research that involves the community in an equitable way through all phases of the research process [15-17]. Over the course of the past 15 years, our CBPR partnership, Rochester Healthy Community Partnership (RHCP), has studied multiple health issues affecting Somalis living in Southeast Minnesota [18]. In this cross-sectional study, we report on the health priorities of a large Somali community-based cohort in a mediumsized US city.

\section{Methods}

This study was conducted in 2018 as part of a larger RHCP survey of Somali participants. The purpose of the survey was to assess the effects of social networks on weight and obesogenic behaviors [19]. Because the planned survey was among the largest reported with a community sample of Somalis, RHCP community partners advocated for an embedded assessment of health priorities more broadly. This was a CBPR study where community and academic members of RHCP worked together in all phases of the study.

\section{Setting and Participants}

Somali community partners recruited participants living in Olmsted County, Minnesota. Eligibility criteria were (1) age 18 or greater, (2) residence in the county, and (3) self-identification as Somali. Recruitment was done in various community locations including homes, offices, sporting events, restaurants, and mosques. Study procedures were approved by the Mayo Clinic Institutional Review Board.

\section{Data Collection}

Data were collected at the time of recruitment, or at another pre-arranged time at the convenience of the study participants. Written surveys available in Somali and English were administered by three bilingual Somali RHCP community partners.

English language survey items were reviewed by an RHCP translation team, which adapted the World Health Organization's translation procedure of forward translation, panel discussion, backward translation, pre-test, cognitive briefing and a consensus on the final instrument by a core group of Somali community partners [20]. We have previously described our approach to translation in a CBPR context [21].

Demographic information collected in the survey included age, gender, country of birth, annual household income, education level, and level of English language proficiency on a 5-point Likert scale.

\section{Measures}

Health priorities among this community sample of Somali adults were assessed at the individual and community levels. Individual health priorities were assessed with the following survey item: 'What are the important health issues for you and your family?'. Perceived community health priorities were assessed as follows: 'What are the most important health issues for your community?'. Participants were able to write up to three responses for each question.

\section{Data Analysis}

Responses to each health priority item were translated by community partners and manually entered into an electronic spreadsheet. Additional data cleaning was done by combining synonymous constructs (e.g., diabetes and type 2 diabetes). Two authors (AAM, KL) then reviewed all responses and sorted them into categories. Demographic and health priority data were reported as counts and frequencies.

\section{Results}

A total of 646 participants responded to the survey. The majority (93\%) of participants were born outside of the US. The mean age was 37.9 years with $43 \%$ female. The majority $(66 \%)$ had a high school level education or less. Annual 
family income was less than $\$ 50,000$ for $92 \%$ of participants and $90 \%$ had health insurance in the last 12 months (Table 1).

\section{Health Priorities}

For the health priority survey items, some survey participants listed three issues while others listed only one. The total responses were 884 for the individual health priorities item and 1037 for the community health priorities item. Responses are shown in Table 2.

\section{Health Priorities for Individuals and Their Families}

The most important health issue for individuals and their families were related to health behaviors, diabetes, and hypertension. Health behaviors accounted for $22.7 \%$ $(n=200)$ of the total responses $(n=881)$. This category included diet $(n=120,13.6 \%)$, exercise $(n=52,5.9 \%)$, and other health behaviors $(n=28,3.2 \%)$. For the diet subcategory, most respondents simply wrote "diet", "healthy

Table 1 Participant demographics $(n=646)$

\begin{tabular}{|c|c|}
\hline Measurement & Total \\
\hline Age, mean (SD) & $37.9(17.1)$ \\
\hline Female gender, $\mathrm{n}(\%)$ & $290(45)$ \\
\hline \multicolumn{2}{|l|}{ Formal schooling completed, n (\%) } \\
\hline 8 grades or less & $165(26)$ \\
\hline Some high school & $64(10)$ \\
\hline High school or GED completed & $194(30)$ \\
\hline Some college or technical school & $147(23)$ \\
\hline College or advanced degree & $68(11)$ \\
\hline \multicolumn{2}{|l|}{ Annual family income, $\mathrm{n}(\%)$} \\
\hline$\$ 0$ to $\$ 9,999$ & $260(41)$ \\
\hline$\$ 10,000$ to $\$ 19,999$ & $102(16)$ \\
\hline$\$ 20,000$ to $\$ 29,000$ & $114(18)$ \\
\hline$\$ 30,000$ to $\$ 49,999$ & $111(18)$ \\
\hline$\$ 50,000$ or higher & $46(7)$ \\
\hline \multicolumn{2}{|c|}{ Health insurance in last 12 months, $\mathrm{n}(\%)$} \\
\hline Yes & $576(90)$ \\
\hline No & $63(10)$ \\
\hline \multicolumn{2}{|l|}{ Country of birth, n (\%) } \\
\hline United States & $45(7)$ \\
\hline Other country & $574(93)$ \\
\hline \multicolumn{2}{|l|}{ English language proficiency, n (\%) } \\
\hline Not at all & $56(9)$ \\
\hline Not very well & $153(24)$ \\
\hline Well & $193(31)$ \\
\hline Very well & $230(36)$ \\
\hline
\end{tabular}

Totals vary due to missing data and combined categories. Gender was missing for 4 participants eating," or "nutrition". The exercise subcategory included responses such as "exercise" or "physical activity." Smoking $(n=7)$ was in the other health behaviors category. For survey participants who listed specific diseases, diabetes represented $18.2 \%(n=160)$ of total responses while hypertension was cited $14.4 \%(n=127)$ of the time. Together, responses in the top three categories represented $55.2 \%$ of the total responses.

\section{Health Priorities for the Community}

The top three responses to the question on the most important health issues for the Somali community were similar to those listed as important for individuals and their families. However, diabetes ( $n=233,22.5 \%$ of 1034 total responses) was the top health issue instead of health behaviors, which was the fourth most cited priority for the community as a whole. The second most important health issue was hypertension $(\mathrm{n}=194,18.8 \%)$. Weight-related issues were the third most cited concern $(n=164,15.9 \%)$. Together, responses in the top three categories were $57.2 \%$ of the total responses (Table 2).

\section{Discussion}

The findings of this study show a significant overlap of the health priorities for Somali individuals and their families as compared to those for the Somali community as a whole. The main priorities were diabetes, hypertension, health behaviors, and weight. Of the health behaviors, diet-related issues were considered a priority over exercise for both individuals/families and the community. Like the previous qualitative study of Somali health priorities [13], these findings showed chronic diseases and health behaviors, especially as related to diet, as priorities for the Somali community.

These priorities stand in juxtaposition to the literature base around Somali health that disproportionately focuses on communicable diseases. This discordance reflects the importance of community voice in assessing health priorities for the Somali diaspora. Priorities of Somali participants in this study that focused on non-communicable diseases are supported by recent literature that highlights a high ageadjusted prevalence of cardiovascular risk factors among Somali populations, including diabetes, hypertension, and obesity $[19,22]$. Furthermore, these risk factors become more prevalent with increased duration of residence among immigrants to Western society [23-25]. Because the average age of Somali immigrants remains relatively low, this reservoir of chronic disease forecasts a potential spike in cardiovascular and cerebrovascular disease events in coming years. Within the framework of Community Organization and the Health Belief Models, the identification of these overlapping 
Table 2 Individual and community health priorities among adult Somali participants

\begin{tabular}{|c|c|}
\hline & Total responses n $(\%)$ \\
\hline \multicolumn{2}{|c|}{ a. What are the important health issues for you and your family? $(\mathrm{n}=881)^{\mathrm{a}}$} \\
\hline Health behaviors & $200(22.7)$ \\
\hline Diet & $120(13.6)$ \\
\hline Exercise & $52(5.9)$ \\
\hline Other health behaviors (e.g. sleep, smoking) & $28(3.2)$ \\
\hline Diabetes & $160(18.2)$ \\
\hline Hypertension & $127(14.4)$ \\
\hline Weight/obesity & $108(12.2)$ \\
\hline Infectious diseases (e.g. viral hepatitis, influenza, tuberculosis) & $39(4.4)$ \\
\hline Hepatitis B or C & $17(1.9)$ \\
\hline Cancer & $27(3.1)$ \\
\hline Gastrointestinal diseases (e.g. reflux, liver disease) & $26(3.0)$ \\
\hline Heart disease & $24(2.7)$ \\
\hline Musculoskeletal (e.g. arthritis, back, knee pain) & $22(2.5)$ \\
\hline Neurological diseases (e.g. stroke, dementia) & $21(2.4)$ \\
\hline Pulmonary diseases (e.g. asthma) & $19(2.2)$ \\
\hline Mental health (e.g. stress, depression) & $18(2.0)$ \\
\hline Health care (e.g. access to care, cost of care) & $9(1.0)$ \\
\hline Other (e.g. environment, eye disorders) & $81(9.2)$ \\
\hline \multicolumn{2}{|c|}{ b. What are the most important health issues for your community? $(n=1034)^{a}$} \\
\hline Diabetes & $233(22.5)$ \\
\hline Hypertension & $194(18.8)$ \\
\hline Weight/obesity & $164(15.9)$ \\
\hline Health behaviors & $158(15.3)$ \\
\hline Diet & $85(8.2)$ \\
\hline Exercise & 48 (4.6) \\
\hline Other health behaviors (e.g. sleep, smoking) & $25(2.4)$ \\
\hline Infectious diseases & $82(7.9)$ \\
\hline Hepatitis B or C & $68(6.6)$ \\
\hline Mental health (e.g. stress, depression) & $45(4.4)$ \\
\hline Cancer & $40(3.9)$ \\
\hline Heart disease & $18(1.7)$ \\
\hline Substance abuse (e.g. drugs, alcohol) & $12(1.2)$ \\
\hline Other (e.g. environment, asthma) & $88(8.5)$ \\
\hline
\end{tabular}

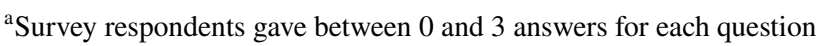

health priorities forms a critical foundational step and paves the way for evaluation of the other key constructs - from assessment of barriers to self-efficacy-in the participatory development of sustainable lifestyle interventions.

Lifestyle factors such as sub-optimal diet and lack of physical activity after migration contribute to these trends, which were reflected in the survey as top health priorities. In a qualitative study with Somali men in Minnesota, barriers to physical activity included sedentary lifestyle, lack of familiarity with exercise equipment, cost of gym membership, and cold weather [26]. Somali women $(\mathrm{N}=30)$ in a focus group study on physical activity reported similar barriers with the addition of the lack of women-only exercise facilities [27].
Discrepancies between the responses for individuals/families and the community were noted for the issues of mental health and substance abuse. Survey respondents listed mental health issues as higher priority for the community $(4.3 \%)$ than for individuals and their families $(2.0 \%)$. There has generally been a discrepancy between the low mental health services utilization and the high need of mental health care in Somali immigrants and refugees [28]. This discrepancy is likely due to stigma associated with psychiatric disease [29-31]. Specific substances that were recorded included "herbs," which, in the Somali community, refers to khat or cannabis. In a study on khat use among Somali mental health service users in London, 80 of a total 172 patients with data on khat use were current users [32]. Khat is a leafy plant that 
contains an amphetamine-like component, D,L-cathinone, that causes stimulating effects [33] and addiction [34], and has been linked to other mental health disorders [35-37].

The major strength of this study is that it assessed health priorities of a large community-based sample of Somali participants. Likewise, community leadership of the project through a CBPR approach facilitated ongoing discussions of community-derived solutions through a social determinants of health lens. The primary limitation of the study is that it was conducted in a single community in Minnesota, with implications for generalizability. Furthermore, the non-probability sampling methods may not have resulted in a truly representative cohort. However, Somali participants were recruited from diverse locations and events by community partners throughout the city. The duration of time lived in the US was not assessed, which may impact health priorities. Finally, it should be noted that this study was conducted before the coronavirus disease 2019 (COVID-19) pandemic, which may have impacted perceived health priorities.

\section{Conclusion}

The findings of this study show a significant overlap of health priorities among Somali individuals and their families compared to perceived priorities for the community as a whole. Health behaviors related to diet and exercise, diabetes, obesity, and hypertension were considered higher priorities than infectious diseases. These health priorities underscore the need for Somali health partnerships to focus on non-communicable diseases.

Funding This publication was supported by NIH Grant No. R01 HL 111407 from the National Heart, Lung, and Blood Institute and by CTSA Grant No. UL1 TR000135 from the National Center for Advancing Translational Science (NCATS). Its contents are solely the responsibility of the authors and do not necessarily represent the official views of the NIH. The funding bodies had no role in study design; in the collection, analysis, and interpretation of data; writing of the manuscript; and in the decision to submit the manuscript for publication.

\section{References}

1. Centers for Disease Control and Prevention, N.C.f.E.a.Z.I.D., Division of Global Migration and Quarantine. Population movements: Somali. Refugee Health Profiles 2018 August 18, 2018. https://www.cdc.gov/immigrantrefugeehealth/profiles/somali/ populationMovements.html. Accessed 2020.

2. (UNHCR), U.H.C.f.R. Resettlement at a glance (January-December 2019). 2020 2/05/2020. https://www.unhcr.org/en-us/prote ction/resettlement/5e31448a4/resettlement-fact-sheet-2019.html. Accessed 15 Feb 2020.

3. Adair R, Nwaneri MO. Communicable disease in African immigrants in Minneapolis. Arch Intern Med. 1999;159(1):83-5.
4. Kempainen R, et al. Mycobacterium tuberculosis disease in Somali immigrants in Minnesota. Chest. 2001;119(1):176-80.

5. Venters H, Gany F. African immigrant health. J Immigr Minor Health. 2011;13(2):333-44.

6. Wieland ML, et al. Screening for tuberculosis at an adult education center: results of a community-based participatory process. Am J Public Health. 2011;101(7):1264-7.

7. Commodore-Mensah Y, et al. Hypertension, overweight/obesity, and diabetes among immigrants in the United States: an analysis of the 2010-2016 National Health Interview Survey. BMC Public Health. 2018;18(1):773.

8. Ramos M. Health of resettled Iraqi refugees-San Diego County, California, October 2007-September 2009. MMWR Morb Mortal Wkly Rep. 2010;59(49):1614-8.

9. Asgary R, et al. Communicable and non-communicable diseases among recent immigrants with implications for primary care; a comprehensive immigrant health approach. J Immigr Minor Health. 2011;13(6):990-5.

10. Yun K, et al. High prevalence of chronic non-communicable conditions among adult refugees: implications for practice and policy. J Community Health. 2012;37(5):1110-8.

11. Ingram J. The health needs of the Somali community in Bristol. Community Pract. 2009;82(12):26-9.

12. Filippi MK, et al. A pilot study of health priorities of Somalis living in Kansas City: laying the groundwork for CBPR. J Immigr Minor Health. 2014;16(2):314-20.

13. Janz NK, Becker MH. The health belief model: a decade later. Health Educ Q. 1984;11(1):1-47.

14. Johnson CE, Ali SA, Shipp MP. Building community-based participatory research partnerships with a Somali refugee community. Am J Prev Med. 2009;37(6 Suppl 1):S230-6.

15. Israel BA, et al. Review of community-based research: assessing partnership approaches to improve public health. Annu Rev Public Health. 1998;19:173-202.

16. Horowitz CR, et al. Effective recruitment of minority populations through community-led strategies. Am J Prev Med. 2009;37(6 Suppl 1):S195-200.

17. Shalowitz MU, et al. Community-based participatory research: a review of the literature with strategies for community engagement. J Dev Behav Pediatr. 2009;30(4):350-61.

18. Rochester Healthy Community Partnership of Rochester, MN. 2020. https://rochesterhealthy.org.

19. Njeru JW, et al. Social networks and obesity among Somali immigrants and refugees. BMC Public Health. 2020;20(1):238.

20. (WHO), W.H.O. Process of translation and adaptation of instruments. 2020. https://www.who.int/substance_abuse/research_tools /translation/en/. Accessed 20 Apr 2020.

21. Formea CM, et al. Lessons learned: cultural and linguistic enhancement of surveys through community-based participatory research. Prog Community Health Partnersh. 2014;8(3):331-6.

22. Njeru JW, et al. High rates of diabetes mellitus, pre-diabetes and obesity among Somali immigrants and refugees in Minnesota: a retrospective chart review. J Immigr Minor Health. 2016;18(6):1343-9.

23. Goel MS, et al. Obesity among US immigrant subgroups by duration of residence. JAMA. 2004;292(23):2860-7.

24. Steffen PR, et al. Acculturation to Western society as a risk factor for high blood pressure: a meta-analytic review. Psychosom Med. 2006;68(3):386-97.

25. Koya DL, Egede LE. Association between length of residence and cardiovascular disease risk factors among an ethnically diverse group of United States immigrants. J Gen Intern Med. 2007;22(6):841-6.

26. Mohamed AA, et al. Physical activity among Somali men in Minnesota: barriers, facilitators, and recommendations. Am J Mens Health. 2014;8(1):35-44. 
27. Devlin JT, et al. Determinants of physical activity among Somali women living in Maine. J Immigr Minor Health. 2012;14(2):300-6.

28. McCrone P, et al. Mental health needs, service use and costs among Somali refugees in the UK. Acta Psychiatr Scand. 2005;111(5):351-7.

29. Boynton $\mathrm{L}$, et al. The role of stigma and state in the mental health of Somalis. J Psychiatr Pract. 2010;16(4):265-8.

30. Piwowarczyk L, et al. Congolese and Somali beliefs about mental health services. J Nerv Ment Dis. 2014;202(3):209-16.

31. Bettmann JE, et al. Somali refugees' perceptions of mental illness. Soc Work Health Care. 2015;54(8):738-57.

32. Tulloch AD, et al. Khat use among Somali mental health service users in South London. Soc Psychiatry Psychiatr Epidemiol. 2012;47(10):1649-56.

33. Wagner GC, et al. Neurochemical similarities between d, 1-cathinone and d-amphetamine. Drug Alcohol Depend. 1982;9(4):279-84.
34. Krikorian AD. Kat and its use: an historical perspective. J Ethnopharmacol. 1984;12(2):115-78.

35. Odenwald $\mathrm{M}$, et al. Khat use as risk factor for psychotic disorders: a cross-sectional and case-control study in Somalia. BMC Med. 2005;3:5.

36. Odenwald $\mathrm{M}$, et al. The consumption of khat and other drugs in Somali combatants: a cross-sectional study. PLoS Med. 2007;4(12):e341.

37. Odenwald $\mathrm{M}$, et al. Use of khat and posttraumatic stress disorder as risk factors for psychotic symptoms: a study of Somali combatants. Soc Sci Med. 2009;69(7):1040-8.

Publisher's Note Springer Nature remains neutral with regard to jurisdictional claims in published maps and institutional affiliations. 